\title{
Resilience and related factors as predictors of relapse risk in patients with substance use disorder: A cross-sectional study
}

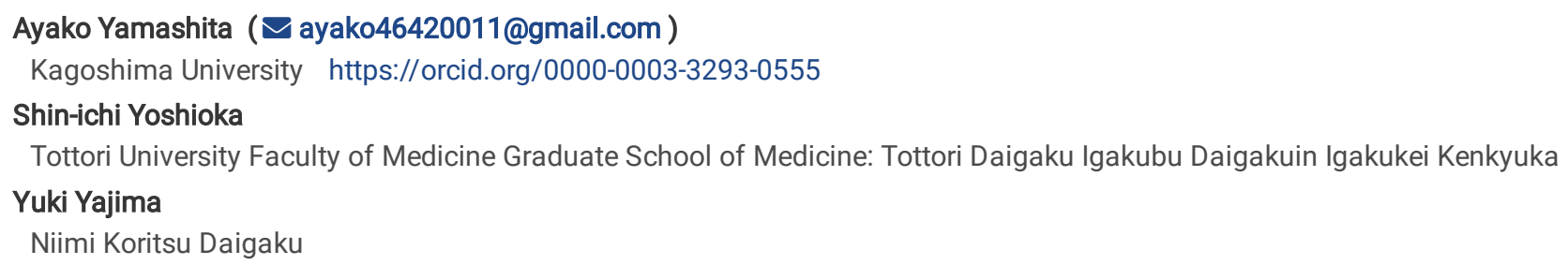

Research

Keywords: resilience, recurrence, substance use disorder, employment, recovery

Posted Date: January 29th, 2021

DOI: https://doi.org/10.21203/rs.3.rs-155858/v1

License: (c) (1) This work is licensed under a Creative Commons Attribution 4.0 International License. Read Full License 


\section{Abstract}

Aim: Resilience is an essential concept in discussions of substance use disorder recovery, referring to the inherent ability to naturally recover in the face of adverse conditions. This study's objective was to shed light on resilience and related factors that affect relapse risk in patients with SUDs. Method : Fifty-two SUD patients were given a self-administrated questionnaire from February to April 2015, consisting of question items for sociodemographic characteristics, relapse risk (Stimulant Relapse Risk Scale), and resilience (Bidimensional Resilience Scale). Scale scores were tested for associations with subject attributes, after which resilience's effects on relapse risk were analyzed using correlation and multiple regression (forced-entry) analyses. Results : Stimulants were the most common drug of abuse ( $n=26,21.7 \%$; multiple answers). Reduced relapse risk was significantly associated with current employment (Std. $\beta \bigotimes-0.446, \mathrm{P}<0.05)$. Conclusion : Our findings demonstrate the necessity of recovery support to enhance acquired resistance in SUD patients in order to prevent relapses. Reinforcing employment support services and encouraging patients to continue treatment were suggested as potentially effective measures to enhance resilience in individuals with SUDs on their road to recovery.

\section{Introduction}

Substance use disorders (SUDs) are a group of mental illnesses characterized by impulsive behavior and a persistent, strong desire to ingest a given substance, associated with drug-seeking behavior, withdrawal symptoms, and tolerance. ${ }^{1}$

They can involve a wide variety of drugs, including stimulants, analgesics, hypnotics, and narcotics ${ }^{2}$, potential for mental and/or physical dependence depends in part on the substance's mechanism of action. According to 2017 estimates, $2.3 \%$ of Japan's population have used a drug of abuse at least once in their lives. Cannabis is the most commonly used substance, with an estimated lifetime prevalence of $1.4 \%{ }^{3}$ One 2014 study of SUD patients receiving inpatient treatment in Japan reported stimulants as the most common drug of abuse, followed by legal highs and prescription drugs, noting problems associated with the striking jump in the latter two. ${ }^{4}$

Two factors are expected to dramatically increase the number of people with SUDs supervised under probation: Japan's extremely high recidivism rate among stimulant offenders (74.1\%), and the 2016 introduction of a legal framework to partially suspend the execution of sentences for drug-related and other criminal offenses. ${ }^{5}$ However, some commentators have called for an urgent overhaul of Japan's SUD treatment system, noting the paucity of facilities dedicated to drug rehabilitation, and the resulting low rates of treatment among those who need it. ${ }^{6}$

Studies have raised cognitive-behavioral therapy (CBT) and stage-transition models as effective interventions for drug dependence ${ }^{7}$, and demonstrated the importance of self-awareness and its association with drug cessation. ${ }^{8}$ Coping skills, recreational activities, and social support have been reported to effectively encourage continued abstinence. ${ }^{9}$

Drug dependence can be considered a chronic disease based on its pathology and symptoms, meaning SUD patients should be provided with continuous therapy and support even after they have stopped taking the offending substance. Moreover, since denial is a characteristic symptom of drug dependence ${ }^{10}$, it is imperative for patients to gain self-management skills by deeply understanding their disease and personally feeling the benefits of recovery. Participation in recovery group meetings held in self-help groups and treatment centers helps substance abusers to improve self-disclosure. ${ }^{11}$ This strengthens resilience, a crucial psychological trait for preventing relapse.

Self-help group participation can constitute a 'spiritual' experience, enhancing self-disclosure ${ }^{12}$ and allowing attendees to recognize their own experiences in the stories of others. ${ }^{13}$

Resilience is a concept that has attracted attention in recent years in discussions about recovery from substance dependence. ${ }^{14}$ Resilience is the ability to adapt to adverse conditions ${ }^{15-17}$, regarded in the field of psychiatry as a critical component of recovery. Resilience does not reflect personal weakness; it can be enhanced in any and everyone. ${ }^{18}$

Resilience can be subcategorized into innate resilience, a product of inherent, individual factors, and acquired resilience, which can be modified and strengthened by a variety of environment factors. ${ }^{19,20}$ This trait is crucial to the concept of recovery as it relates to people with mental disorders. Recovery has been defined as "a process that allows people [with diseases or disabilities] to actively participate in their life, work, study, and community; affected individuals may conceptualize it as the ability to lead a rich and productive life despite their disability, while others may see it as a reduction or mitigation of those individuals' symptoms."21 While individual factors certainly play a role in SUD recovery, it is acquired resilience-related factors that are predicted to strongly drive recovery, helping people to grow and develop as they combat their disease.

This survey-based investigation aimed to shed light on relapse risk in SUD patients attending self-help groups, along with its association with resilience and related factors, in the hope of providing some insight into how to support SUD recovery efforts. 


\section{Methods}

\section{Study design}

This study is cross-sectional study design.

\section{Study samples}

An anonymous, self-administered questionnaire survey was given to 80 SUD patients who participated in self-help group meetings across Japan and who agreed with the study's objective. It was conducted from February to April 2015.

\section{Demographics}

Demographic features constituting the questionnaire were as follows: age, gender, whether or not they lived with another person or had a key person with whom to consult in their lives, employment status, age when diagnosed with SUD, treatment time period, abstinence period, number of sessions and time period participating in self-help groups, types of dependence drugs, other psychological disorders, and physical disorders.

\section{Resilience}

This study used the bidimensional resilience scale developed in Japan. ${ }^{22,} 23$ This scale is comprised of innate-resilience factors (12 questions related to individual factors) and acquired-resilience factors (9 questions related to environmental factors). The innate resilience factors indicate those that are strongly related to the individual's inherent nature; acquired factors indicate learned methods of resilience. This scale uses a fivepoint rating for the questionnaire with higher total scores indicating greater resilience. In this study, the Cronbach's a coefficient for the bidimensional resilience scale was 0.910; thus, internal consistency was maintained. This scale uses a five-point rating for the questionnaire with higher total scores indicating greater resilience. In this study, the Cronbach's a coefficient for the bidimensional resilience scale was 0.797 ; thus, internal consistency was maintained.

\section{Stimulant Relapse Risk}

To measure risk of SUD relapse, we used the Stimulant Relapse Risk Scale (SRRS). ${ }^{24}$ This scale consists of 30 items on five sub-scales as follows: Anxiety and intention to use drug (AI); Emotionality problem (EP); Compulsivity for drug (CD); Positive expectancies and lack of control over drug (PL); and Lack of negative expectancy for the drug (NE). The SSRS includes 5 items to measure insight into mental condition: awareness of illness (AI). SRRS score is defined as the average (or combined total) of the five sub-scale scores. When five supplementary items indicating the respondent's intensity of awareness of their illness were included, this scale consisted of a total of 35 items. Questions used a three-step rating scale, with higher scores indicating greater risk of using the drug of dependence. In this study, the Cronbach's a coefficient for the 35 items in the SRRS was 0.883; thus, internal consistency was maintained.

\section{Statistical analysis}

First, resilience and SRRS score distributions were tested for normality using the Shapiro-Wilk test. Resilience and relapse risk were then compared between subgroups with different demographic characteristics using the Student's t-test. Next, Pearson product correlation coefficients were calculated among the following variables: current age, age at diagnosis, treatment time period, abstinence period, acquired resilience score, innate resilience score, and SRRS total score. Finally, multiple linear regression analysis via the forced entry procedure was performed using relapse risk as the dependent variable, innate and acquired resilience as independent variables, and the following control variables: current age, employment status (dummy variable: $1=$ employed, $0=$ unemployed), age at diagnosis, treatment time period, and abstinence period. Variance inflation factors (VIF) were calculated for each independent variable to check for collinearity in multiple regression analysis: each measured < 4.0, indicating minimal multicollinearity.

Statistical analyses were performed using IBM SPSS $24.0 \mathrm{~J}$ for Windows (SPSS, Chicago, IL), and the significance level was set at $5 \%$ for all tests.

\section{Ethical considerations}

After receiving approval from the Tottori University Faculty of Medicine Ethics Review Committee (approval number 2646), this study was conducted in accordance with the fundamental principles set forth in the Helsinki Declaration. Informed consent was obtained from each participant after the procedure(s) had been fully explained.

\section{Results}

\section{Subject attributes}


Surveys were given to 80 individuals who attended support meetings at three drug addiction rehabilitation centers and one medical center specializing in the treatment of substance dependence. Surveys were collected from 52 of them (recovery rate: $65.0 \%$ ). Table 1 details their demographics and other attributes.

Subjects' average age was $37.2 \pm 10.0$ years (range: 20 - 66); their average age at diagnosis was $29.3 \pm 9.4$ years (15 - 52 ). Men comprised the majority ( 90\%) of the group. Approximately $30 \%$ of subjects were currently employed. On average, subjects had received treatment for $67.0 \pm$ 68.9 months ( 5 - 282), and abstained from drug use for $31.9 \pm 30.2$ months $(0$ - 132). They attended a self-help group $5.7 \pm 2.0$ times $(0$ - 7$)$ per week on average. Table 2 shows the population's drugs of dependence. Stimulants were the most common drug of abuse, taken by 26 subjects (21.7\%; multiple answers).

The study population was actively and continuously participating in treatment: $73.1 \%$ were visiting hospital or receiving inpatient treatment for SUDs, while the complete sample attended meetings in SUD rehabilitation centers or self-help group $5.7 \pm 2.0$ times per week on average. In addition, about $90 \%$ were living with someone else, or had someone with whom they could talk about their SUD. The average abstinence period was 2 years 8 months. These statistics suggest that our population consisted of individuals receiving continuing treatment for SUDs who maintained good interpersonal relationships and had some form of social support.

The fact that subjects were abstinent for only 2 years 8 months on average despite receiving treatment for about 6 years suggests that people with SUDs require a long time to break away from their disease.

\section{Scale scores}

Table 3 presents resilience and relapse risk scale data.

\section{Attributes versus resilience and SRRS scores}

Table 4 contains the results of statistical comparisons between attributes and instrument scores. Relapse risk was significantly lower in employed subjects $(P<0.01)$ and those with a comorbid mental illness $(P<0.05)$.

\section{Correlation analysis}

Pearson correlation coefficients were calculated among the following variables: current age, age at diagnosis, treatment time period, abstinence period, and total scores for each scale (Table 5). Current age positively and significantly correlated with age at diagnosis $(r=0.600, P<0.01)$ and treatment time period $(r=0.492, P<0.01)$. In addition, treatment time period positively and significantly correlated with abstinence period $(r=$ $0.367, \mathrm{P}<0.01)$. Innate and acquired resilience exhibited a significant correlation as well $(r=0.585, \mathrm{P}<0.01)$. Total SRRS score was significantly and negatively correlated with both innate resilience $(r=-0.310, P<0.01)$ and acquired resilience $(r=-0.314, P<0.01)$.

\section{Relapse risk-related factors}

Only patients without missing data for scale items were included in this sub-analysis ( $\mathrm{n}=38)$. Multiple regression analysis (forced entry) was conducted using SSRS total score as the dependent variable and current age, employment status, age at diagnosis, treatment time period, abstinence period, and acquired resilience as independent variables. The model's multiple correlation coefficient (R) was 0.562 (coefficient of multiple determination $\left.\left[R^{2}\right]=0.315\right)(P<0.05)$. Table 6 contains the standard partial regression coefficients between SSRS total score and each independent variable. Reduced relapse risk was significantly associated with current employment $(S t d . \beta \rrbracket-0.446, P<0.05)$.

\section{Discussion}

Study participants had innate and acquired resilience scores of $35.3 \pm 7.3$ and $29.4 \pm 4.7$, respectively. This study identified employment status and acquired resilience as two factors significantly associated with relapse risk.

First, our population had innate and acquired resilience scores of $35.3 \pm 7.3$ and $29.4 \pm 4.7$, respectively. A previous study using the same Bidimensional Resilience Scale observed respective scores of $38.2 \pm 8.1$ and $30.1 \pm 5.5$ in patients with alcohol use disorders. ${ }^{11}$ While acquired resilience scores did not greatly differ between the two studies, our subjects' innate resilience score was 2.9 points lower. A previous study reported low levels of resilience in individuals with a SUD. ${ }^{25}$ However, while our study found no association between relapse risk and innate resilience, we did identify a weak association between it and acquired resilience. This suggest that resilience is enhanced as patients recover from SUDs. The idea of a resilience-related mechanism that protects people from psychological risk has empirical support, with findings demonstrating such a mechanism to reduce the effects of said risks, decrease negative chain reactions, and establish and maintain self-esteem and self-efficacy. ${ }^{26}$ This indicates that interventions intended to instill self-esteem and self-efficacy in patients during their recovery should primarily involve modifying their environment, such as changing or avoiding interactions with others formerly associated with the drug of abuse, and correcting cognitive distortions. ${ }^{27}$ Mindfulness's efficacy in correcting cognitive distortions has been demonstrated in patients with SUDs. ${ }^{28}$ 
Recent years have seen the application of workbook-based CBT (Cognitive Behavioral Therapy) based on evidence from the Matrix Model in the USA, with proven results. ${ }^{29}$

Our findings that relapse risk was significantly and negatively correlated with innate and acquired resilience, with high acquired resilience predicting reduced relapse risk, illustrate the need for SUD recovery to focus on enhancing resilience. SUD prevention-related research on resilience has reported that such efforts to improve resilience need to be started in early childhood. ${ }^{30}$ Moreover, resilience-related research has demonstrated the need for family-based interventions and social support, showing an community affinity-based intervention program to enhance resilience in families with teenagers, a demographic at high risk for alcohol and drug dependence. ${ }^{31}$ This would necessitate programs to improve resilience that utilize CBT and other techniques from children's teenage years. Moreover, resilience building requires a safe and stable treatment environment where individuals can self-disclose with peace of mind: other research has reported resilience to be enhanced through better selfdisclosure by participation in meetings held in self-help groups and treatment centers aimed at preventing relapse in alcohol dependence. ${ }^{32}$

Substance dependence must be treated using a dual approach, targeting withdrawal symptoms due to physical dependence as well as drugseeking behavior due to mental dependence. ${ }^{33}$ In addition, continuous therapy combining pharmacological with psychosocial interventions is essential to SUD recovery. We found that subjects with a comorbid mental illness were at significantly lower risk of relapse than those without: perhaps the fact that these individuals had already been receiving continued treatment is in part responsible.

We identified ongoing employment as a factor related to relapse risk. This finding could also be explained by subjects gaining employment as a result of reduced relapse risk. Employment is a form of self-actualization, which leads to improved self-esteem and self-efficacy. Employment can be equally conceived of as a desire to engage with the recovery process, a form of empowerment, a sign of taking personal responsibility, and as a significant role in someone's life. ${ }^{34}$ Employment history, marketable skills, and barriers have all been identified as essential elements of vocational assessments for SUD patients performed in drug abuse treatment programs. ${ }^{35}$ Punishments for illegal drug use and difficulties with living impairment due to dependence can cause people to leave their jobs. However, employment's association with acquired resilience shows the need for recovery programs to incorporate vocational support, tailored to a patient's stage in the recovery process. Employment support services for individuals with SUDs should be reinforced as a community-based measure to support their recovery.

This study's cross-sectional design prevents us from drawing inferences about the recovery process over time in individuals with SUDs. In addition, given the small sample size, our findings may not necessarily capture all facets of SUDs at the population level. The reason why multiple regression analysis showed no significant difference between the regression risk and the acquired-resilience may be due to the small sample size. Furthermore, there may be individual differences in certain respects, such as how quickly and severely dependence forms, given the great variation in drugs of abuse, and their biological and psychoactive properties accordingly. Conducting a longitudinal study to shed light on how resilience changes during the recovery process is a task for future study.

\section{Conclusion}

Our findings provide some insight into the therapeutic benefits of recovery support of patients with SUD. Specifically, we observed heightened relapse risk in patients with low acquired resilience, demonstrating that recovery support initiatives need to enhance this ability in SUD patients in order to prevent relapse. Moreover, the association of acquired resilience with employment status means that recovery programs need to incorporate employment support, tailored to patients' progress in the recovery process. Recovery support to enhance resilience in individuals with SUDs should include means to improve employment support services and ensure patients continue treatment in the long term.

Doe J. Title of subordinate document. In: The dictionary of substances and their effects. Royal Society of Chemistry. 1999.

http://www.rsc.org/dose/title of subordinate document. Accessed 15 Jan 1999.

\section{Abbreviations}

Al: Anxiety and intention to use drug

Al: awareness of illness

CBT: Cognitive-behavioral therapy

CD: Compulsivity for drug

EP: Emotionality problem

$\mathrm{N}$ : Number of participants

NE: Lack of negative expectancy for the drug 
PL: Positive expectancies and lack of control over drug

SD: Standard deviation

SRRS: Stimulant Relapse Risk Scale

SUDs: Substance use disorders

\section{Declarations}

\section{Ethics approval and consent to participate}

After receiving approval from the Tottori University Faculty of Medicine Ethics Review Committee (approval number 2646), this study was conducted in accordance with the fundamental principles set forth in the Helsinki Declaration. Informed consent was obtained from each participant after the procedure(s) had been fully explained.

\section{Consent for publication}

The authors have obtained consent to publish from the participants.

\section{Availability of data and materials}

The data analyzed in the current study are not publicly available due to confidential and potentially sensitive information. Data are available from the corresponding author on request.

\section{Competing interests}

The authors declare that they have no competing interests.

\section{Funding}

This study was completed as part of research conducted via the Grant-in-Aid for Scientific Research (C) (Grant Number 15K11835).

\section{Authors' contributions}

Conception and design of the study: A.Y., S.Y.

Acquisition and analysis of data: A.Y., S.Y., Y.Y.

Drafting of the manuscript and table: A.Y., S.Y., Y.Y.

All authors gave substantial contribution to and agreement on the final version of the manuscript.

\section{Acknowledgements}

We would like to express our sincerest, heartfelt gratitude to everyone who has cooperated with this study.

\section{References}

1. World Health Organization. International Statistical Classification of Diseases and Related Health Problems 10th Revision, ICD-10 Version. 2016. https://icd.who.int/browse10/2016/en\#. Accessed 20 Aug 2020.

2. American Psychiatric Association. Diagnostic \& Statistical Manual of Mental Disorders, 5th edn. American Psychiatric Association Publishing, Washington, DC, 2013.

3. Shimane T, Qiu D, Wada K. 2017 Nationwide General Population Survey on Drug Use in Japan.In: Shimane T.Monitoring Survey on Substance Abuse and Dependency and Recovery Support for Substance Abusers and Their Families: Annual Report of Ministry of Health, Labour and Welfare, 2018; 7-134. https://www.ncnp.go.jp/nimh/yakubutsu/report/pdf/J_NGPS_2017.pdf (in Japanese). Accessed 18 Aug 2020.

4. Matsumoto T, Ito T, Takano A, Tanibuchi Y, Funada D, Tachimori H. Survey on Substance-Related Psychiatric Diseases in Japanese Psychiatric Facilities: In: Shimane T. 2016 Ministry of Health, Labour and Welfare Grants-in-aid for Scientific Research, Research on Regulatory Science of Pharmaceuticals and Medical Devices: Annual Report on the Current Status of Illicit and Designer Drug Abuse and 
Dependency and Interventions to Promote Social Recovery in People with Substance Dependency, 2017; 101-136.

https://www.ncnp.go.jp/nimh/yakubutsu/report/pdf/J_NMHS_2016.pdf (in Japanese). Accessed 20 Aug 2020.

5. National Center of Neurology and Psychiatry, Research and Training Institute Ministry of Justice. Understanding and Supporting Stimulants Criminals 2018. 2019;3-4 (in Japanese).

6. Matsumoto T, Kobayashi 0 . What is the Japanese mental health service lacking for drug dependence rehabilitation?. Nihon Arukoru Yakubutsu Igakkai Zasshi. 2008;43(3), 172-87 (in Japanese).

7. Kaminer Y, Burleson JA, Goldberger R. Cognitive-behavioral coping skills and psychoeducation therapies for adolescent substance abuse. $J$ Nerv Ment Dis. 2002;190(11):737-745.

8. DiClemente CC, Prochaska JO, Fairhurst SK, Velicer WF, Velasquez MM, Rossi JS. The process of smoking cessation: an analysis of precontemplation, contemplation, and preparation stages of change. J Consult Clin Psychol. 1991;59(2):295-304.

9. Litt MD, Kadden RM, Kabela-Cormier E, Petry NM. Changing network support for drinking: network support project 2-year follow-up. J Consult Clin Psychol. 2009;77(2):229-242.

10. Williams AR, Olfson M, Galanter M. Assessing and improving clinical insight among patients "in denial". JAMA Psychiatry. 2015;72(4):303304. doi:10.1001/jamapsychiatry.2014.2684

11. Yamashita A, Yoshioka SI. Resilience Associated with Self-Disclosure and Relapse Risks in Patients with Alcohol Use Disorders. Yonago Acta Med. 2016;59(4):279-287.

12. Mallow AJ. Self-disclosure. Reconciling psychoanalytic psychotherapy and alcoholics anonymous philosophy. J Subst Abuse Treat. 1998;15(6):493-498.

13. Galanter M, Dermatis H, Post S, Sampson C. Spirituality-based recovery from drug addiction in the twelve-step fellowship of narcotics anonymous. J Addict Med. 2013;7(3):189-195.

14. Bartone PT, Hystad SW, Eid J, Brevik JI. Psychological hardiness and coping style as risk/resilience factors for alcohol abuse. Mil Med. 2012;177(5):517-524.

15. Rutter M. Resilience, competence, and coping. Child Abuse Negl. 2007;31(3):205-209.

16. Collishaw S, Pickles A, Messer J, Rutter M, Shearer C, Maughan B. Resilience to adult psychopathology following childhood maltreatment: evidence from a community sample. Child Abuse Negl. 2007;31(3):211-229.

17. Dyer JG, McGuinness TM. Resilience: analysis of the concept. Arch Psychiatr Nurs. 1996;10(5):276-282.

18. American Psychological Association. What is resilience? The Road to Resilience. 2016. [Cited 20 Aug 2020.] Available from https://www.apa.org/helpcenter/road-resilience.

19. Luthar SS, Cicchetti D, Becker B. The construct of resilience: a critical evaluation and guidelines for future work. Child Dev. 2000;71(3):543562.

20. Hirano M. Review of resilience from the viewpoints of its innate and acquired aspects. Bulletin of the Graduate School of Education, the University of Tokyo. 2012; 52: 411-417 (in Japanese).

21. Anthony WA. Recovery from mental illness: the guiding vision of the mental health service system in the 1990s. Psychiatr Rehabil J. 1993; 16(4):11-23.

22. Hirano M. Validity of the bidimensional resilience scale for junior high and high school students: An analysis using the twin method. The Japanese Journal of Personality. 2011; 20(1): 50-52 (in Japanese).

23. Hirano M. A Study of the Classification of Resilience Factors: Development of the Bidimensional Resilience Scale (BRS). The Japanese Journal of Personality. 2010;19(2): 94-106 (in Japanese).

24. Ogai Y, Haraguchi A, Kondo A, et al. Development and validation of the Stimulant Relapse Risk Scale for drug abusers in Japan. Drug Alcohol Depend. 2007;88(2-3):174-181.

25. Belcher AM, Volkow ND, Moeller FG, Ferré S. Personality traits and vulnerability or resilience to substance use disorders. Trends Cogn Sci. 2014;18(4):211-217.

26. Luthar SS, Cicchetti D, Becker B. The construct of resilience: a critical evaluation and guidelines for future work. Child Dev. 2000;71(3):543562.

27. Rutter M. Psychosocial resilience and protective mechanisms. Am J Orthopsychiatry. 1987;57(3):316-331.

28. Priddy SE, Howard MO, Hanley AW, Riquino MR, Friberg-Felsted K, Garland EL. Mindfulness meditation in the treatment of substance use disorders and preventing future relapse: neurocognitive mechanisms and clinical implications. Subst Abuse Rehabil. 2018;9:103-114.

29. Shoptaw S, Rawson RA, McCann MJ, Obert JL. The Matrix model of outpatient stimulant abuse treatment: evidence of efficacy. J Addict Dis. 1994;13(4):129-141.

30. Masten AS. Ordinary magic: Resilience processes in development. American Psychologist 2001; 56(3): $227-238$. 
31. Johnson K, Bryant DD, Collins DA, Noe TD, Strader TN, Berbaum M. Preventing and reducing alcohol and other drug use among high-risk youths by increasing family resilience. Soc Work. 1998;43(4):297-308.

32. Dunn KE, Fingerhood M, Wong CJ, Svikis DS, Nuzzo P, Silverman K. Employment-based abstinence reinforcement following inpatient detoxification in HIV-positive opioid and/or cocaine-dependent patients. Exp Clin Psychopharmacol. 2014;22(1):75-85.

33. Yamashita A, Oriyama S, Watanabe K. Factors that Influence the Drug Stopping of Patients with Drug Dependence: In Relation to their Quality of Life and Self-Esteem, Journal of Japanese Society of Nursing Research. 2013;36(2):47-57 (in Japanese).

34. Ragins M, Medical Director MHA Village. A Road to Recovery. In: Mental Health America of Los Angeles (ed.). Mental Health America of Los Angeles, Los Angeles, 2010.

35. Bowden K, Goodman D. Barriers to employment for drug dependent postpartum women. Work. 2015;50(3):425-432.

\section{Tables}

Table 1.

Demographic characteristics of the sample

\begin{tabular}{|c|c|c|}
\hline & Values & mean $\pm S D$, (Range) \\
\hline Number of participants & \multicolumn{2}{|l|}{52} \\
\hline Gender (\% male) & \multicolumn{2}{|l|}{88.5} \\
\hline \multicolumn{2}{|l|}{ Age (years), (Range) } & $37.2 \pm 10.0,(20-66)$ \\
\hline Employment status (\% work) & \multicolumn{2}{|l|}{32.7} \\
\hline Presence of key person (\% yes) & \multicolumn{2}{|l|}{94.2} \\
\hline Living with someone (\% yes) & \multicolumn{2}{|l|}{86.5} \\
\hline \multicolumn{3}{|l|}{ Treatment state $(n)$} \\
\hline Outpatient & \multicolumn{2}{|l|}{37} \\
\hline Inpatient & \multicolumn{2}{|l|}{1} \\
\hline Untreated & \multicolumn{2}{|l|}{4} \\
\hline Cessation of treatment & \multicolumn{2}{|l|}{3} \\
\hline Unknown & \multicolumn{2}{|l|}{7} \\
\hline \multicolumn{2}{|c|}{ Age when diagnosed with SUD (years), (Range) } & $29.3 \pm 9.4,(15-52)$ \\
\hline \multicolumn{2}{|c|}{ Treatment time period (months), (Range) } & $67.0 \pm 68.9,(5-282)$ \\
\hline \multicolumn{2}{|c|}{ Abstinence period (months), (Range) } & $31.9 \pm 30.2,(0-132)$ \\
\hline \multicolumn{2}{|c|}{ Number of sessions and time period participating in self-help groups (weekly) } & $5.7 \pm 2.0$ \\
\hline \multicolumn{2}{|l|}{ Other psychological disorders (n) } & 14 \\
\hline \multicolumn{2}{|l|}{ Physical disorders (n) } & 14 \\
\hline
\end{tabular}


Table 2.

Types of drugs of abuse among subjects

\begin{tabular}{|lcc|}
\hline Items & N & $\%$ \\
\hline Stimulant & 26 & 21.7 \\
\hline Alcohol & 18 & 15.0 \\
\hline Prescription drugs & 21 & 17.5 \\
\hline thinner & 13 & 10.8 \\
\hline Others & 16 & 13.3 \\
\hline synthetic cannabinoid & 12 & 10.0 \\
\hline Cannabis & 9 & 7.5 \\
\hline Opioid & 1 & 0.8 \\
\hline Cocaine & 1 & 0.8 \\
\hline Methylenedioxymethamphetamine & 1 & 0.8 \\
\hline Marijuana & 1 & 0.8 \\
\hline lysergic acid diethylamide & 1 & 0.8 \\
\hline
\end{tabular}

Multiple answers

$\mathrm{N}$ : number of participants

Table 3.

Average scale scores $(N=52)$

\begin{tabular}{|lll|}
\hline Items & mean \pm SD, & (Range) \\
\hline Bidimensional resilience scale & & \\
\hline Innate-resilience & $35.3 \pm 7.3$, & $(23-58)$ \\
\hline Acquired-resilience & $29.4 \pm 4.7$, & $(20-41)$ \\
\hline Stimulant relapse risk scale & & \\
\hline Anxiety and intention to use drug & $14.5 \pm 4.0$, & $(8-23)$ \\
\hline Emotionality problem & $16.5 \pm 4.2$, & $(8-24)$ \\
\hline Compulsivity for drug & $5.5 \pm 2.1$, & $(4-12)$ \\
\hline Positive expectancies and lack of control over drug & $13.0 \pm 3.6$, & $(6-8)$ \\
\hline Lack of negative expectancy for the drug & $5.7 \pm 1.9$, & $(4-10)$ \\
\hline awareness of illness & $11.9 \pm 2.3$, & $(6-15)$ \\
\hline Total & $67.1 \pm 16.5$, & $(43-93)$ \\
\hline
\end{tabular}

$\mathrm{N}$ : number of participants. 
Table 4.

Comparison of attributes resilience scores and relapse risk score

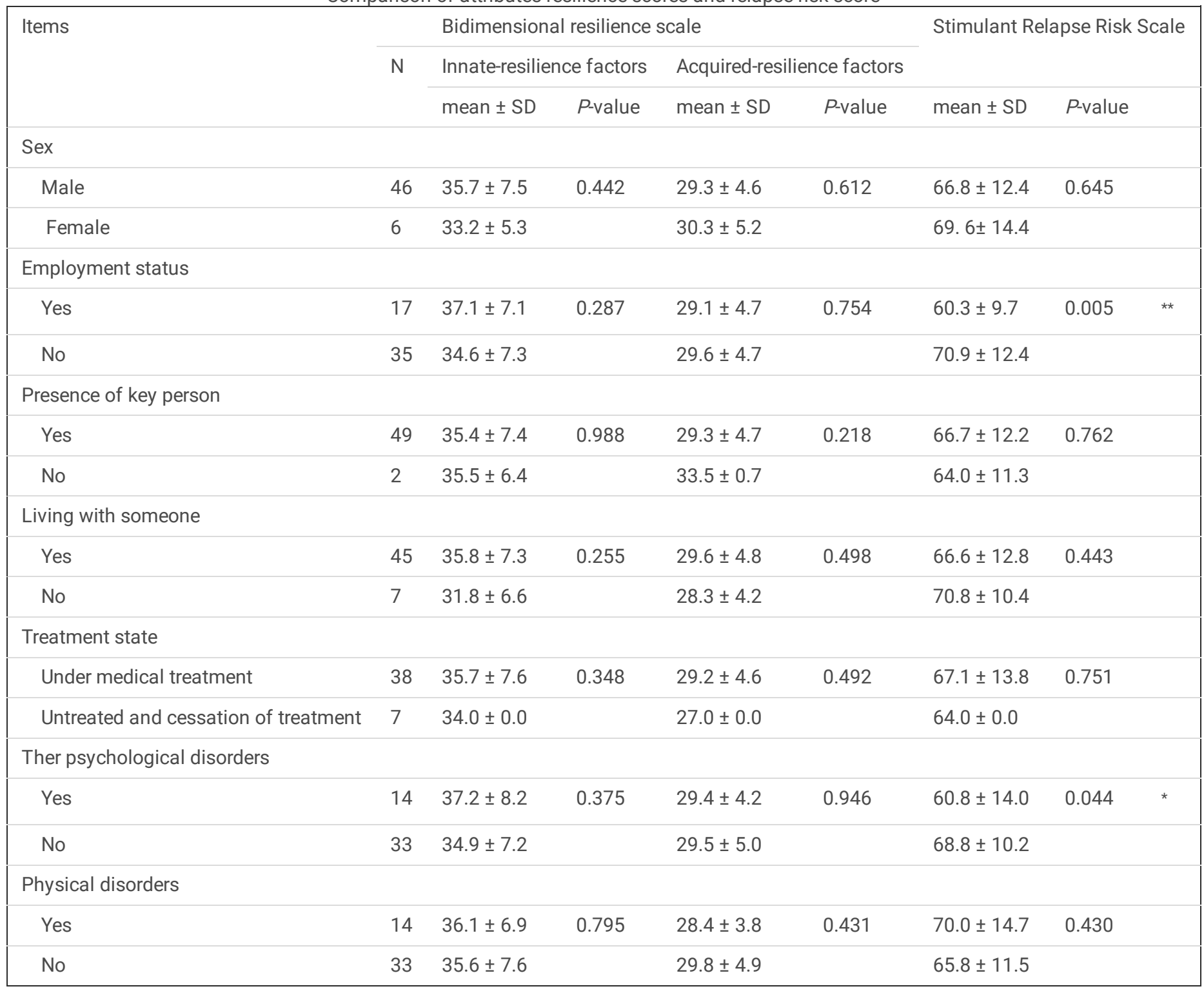

$\mathrm{N}$ : number of participants.

Statistical evaluation is performed by the Student's t-test. $* P<0.5, \star \star P<0.01$

We have used a pairwise method so the total number is different. 
Table 5.

Correlation of the variables $(\mathrm{N}=38)$

\begin{tabular}{|c|c|c|c|c|c|c|c|c|c|c|c|c|c|c|}
\hline & $\begin{array}{l}\text { Stimulant } \\
\text { relapse } \\
\text { risk scale } \\
\text { (total) }\end{array}$ & & Age & & $\begin{array}{l}\text { Age when } \\
\text { diagnosed } \\
\text { with SUD } \\
\text { (years) }\end{array}$ & & $\begin{array}{l}\text { Treatment } \\
\text { time } \\
\text { period } \\
\text { (months) }\end{array}$ & & $\begin{array}{l}\text { Abstinence } \\
\text { period } \\
\text { (months) }\end{array}$ & & $\begin{array}{l}\text { Innate- } \\
\text { resilience }\end{array}$ & & $\begin{array}{l}\text { Acquired- } \\
\text { resilience }\end{array}$ & \\
\hline $\begin{array}{l}\text { Stimulant } \\
\text { relapse } \\
\text { risk scale } \\
\text { (total) }\end{array}$ & 1.000 & & -0.087 & & -0.088 & & 0.057 & & 0.101 & & -0.310 & $\star \star$ & -0.314 & ** \\
\hline Age & -0.087 & & 1.000 & & 0.600 & $\star \star$ & 0.492 & $\star \star$ & 0.189 & & -0.040 & & 0.130 & \\
\hline $\begin{array}{l}\text { Age when } \\
\text { diagnosed } \\
\text { with SUD } \\
\text { (years) }\end{array}$ & -0.088 & & 0.600 & & 1.000 & & -0.027 & & -0.149 & & 0.110 & & 0.123 & \\
\hline $\begin{array}{l}\text { Treatment } \\
\text { time } \\
\text { period } \\
\text { (months) }\end{array}$ & 0.057 & & 0.492 & $\star \star$ & -0.027 & & 1.000 & & 0.367 & $\star \star$ & -0.160 & & 0.145 & \\
\hline $\begin{array}{l}\text { Abstinence } \\
\text { period } \\
\text { (months) }\end{array}$ & 0.101 & & 0.189 & & -0.149 & & 0.367 & ** & 1.000 & & -0.007 & & -0.180 & \\
\hline $\begin{array}{l}\text { Innate- } \\
\text { resilience }\end{array}$ & -0.310 & $\star \star$ & -0.040 & & 0.110 & & -0.160 & & -0.007 & & 1.000 & & 0.585 & ** \\
\hline $\begin{array}{l}\text { Acquired- } \\
\text { resilience }\end{array}$ & -0.314 & $\star \star$ & 0.130 & & 0.123 & & 0.145 & $\star *$ & -0.180 & & 0.585 & ** & 1.000 & \\
\hline
\end{tabular}

$\mathrm{N}$ : number of participants, Pearson's correlation coefficient

Statistical evaluation is performed by the Pearson correlation coefficient. ${ }^{\star *} P \otimes 0.01$

Table 6.

Relapse risk factors $(\mathrm{N}=38)$

\begin{tabular}{|c|c|c|c|c|c|c|}
\hline \multirow[t]{2}{*}{ Variable } & \multirow{2}{*}{$\begin{array}{l}\text { Partial regression } \\
\text { coefficient } \\
(\beta)\end{array}$} & \multirow{2}{*}{$\begin{array}{l}\text { Standardized Partial } \\
\text { regression coefficient } \\
(\beta)\end{array}$} & \multirow[t]{2}{*}{$\mathrm{t}$} & \multirow[t]{2}{*}{$\begin{array}{l}P- \\
\text { value }\end{array}$} & \multicolumn{2}{|c|}{$\begin{array}{l}95.0 \% \\
\text { confidence } \\
\text { interval for B }\end{array}$} \\
\hline & & & & & $\begin{array}{l}\text { Lower } \\
\text { bound }\end{array}$ & $\begin{array}{l}\text { Upper } \\
\text { bound }\end{array}$ \\
\hline Innate-resilience & 0.035 & 0.021 & 0.093 & 0.926 & -0.737 & 0.808 \\
\hline Acquired-resilience & -1.125 & -0.382 & -1.709 & $0.098^{\dagger}$ & -2.469 & 0.219 \\
\hline Age (year) & -0.371 & -0.234 & -0.934 & 0.358 & -1.183 & 0.440 \\
\hline $\begin{array}{l}\text { Employment status } \\
\text { variable } \ \text { Yes 1, No 0) }\end{array}$ & -12.148 & -0.446 & -2.648 & $0.013^{*}$ & -21.515 & -2.780 \\
\hline Age when diagnosed with SUD (year) & 0.182 & 0.106 & 0.476 & 0.637 & -0.598 & 0.961 \\
\hline Treatment time period (month) & 0.040 & 0.224 & 1.034 & 0.310 & -0.039 & 0.119 \\
\hline Abstinence period (month) & 0.044 & 0.101 & 0.558 & 0.581 & -0.117 & 0.205 \\
\hline
\end{tabular}

$\mathrm{N}$ : number of participants,

Statistical evaluation is performed by multiple regression analysis. ${ }^{\dagger} P<0.1,{ }^{\star} P<0.5$

Dependent variable is SRRS Stimulant relapse risk scale(total). 